\title{
COMPARISON OF METHODS OF VISUAL INSPECTION OF CERVIX WITH CERVICAL CYTOLOGY IN DETECTION OF PRE-INVASIVE LESIONS OF CERVICAL CANCER
}

\author{
Kuljit Kaur1, U. T. Bhosale ${ }^{2}$
}

1 Junior Consultant, Department of Obstetrics and Gynaecology, Bharati Vidyapeeth Medical College and Hospital, Sangli. 2 Professor and HOD, Department of Obstetrics and Gynaecology, Bharati Vidyapeeth Medical College and Hospital, Sangli.

\section{ABSTRACT}

\section{BACKGROUND}

Due to increasing incidence of Cervical cancer, a screen-and-treat programs based on visual screening can be cost-effective approach for even the low resource settings.

The aim of this study was to determine the sensitivity, specificity, positive predictive value and accuracy of Visual Inspection with Acetic Acid and Lugol's iodine as a screening method for pre-malignant and malignant lesions of cervix.

\section{MATERIALS AND METHODS}

A prospective study carried out in Department of Obstetrics and Gynaecology in Bharati Medical College and Hospital, Sangli. Women of age 35-65 years with particular Gynaecological complaints attending OBGY OPD from Jan. 2014 - Dec. 2014 included in study after taking the informed consent. Analysis was done.

\section{RESULTS}

Good Sensitivity and Specificity of VIA i.e. $76.9 \%$ and $77.9 \%$ and VILI i.e. $76.9 \%$ and $75.4 \%$ make them better methods to detect precancerous and cancerous lesions of cervix. On comparing VIA and VILI and Pap smear, a significant correlation was found amongst them.

\section{CONCLUSION}

In low resource settings, screening by Pap smear has not been successful in reducing incidence of cervical cancer. VIA and VILI are cheaper and easily available and can be used by medical and paramedical personnel on a large scale basis.

\section{KEYWORDS}

Cervical cancer, VIA, VILI, Pap smear.

HOW TO CITE THIS ARTICLE: Kaur K, Bhosale UT. Comparison of methods of visual inspection of cervix with cervical cytology in detection of pre-invasive lesions of cervical cancer. J. Evolution Med. Dent. Sci. 2016;5(73):5394-5398, DOI: $10.14260 /$ jemds/2016/1224

\section{INTRODUCTION/BACKGROUND}

According to the World Health Organisation, cervical cancer is the second most common type of cancer among females and was responsible for over 250,000 deaths in 2005. Approximately, $80 \%$ of these deaths occurred in developing countries. It constitutes $9.5 \%$ of all cancers, $25 \%$ of all cancers in women, $68.5 \%$ of Gynaecologic cancers. The lowest incidence $2.6 / 100000$ is noted in Israel. India with an incidence of 47.2/100000 women stands third highest in world incidence. The lifetime risk of carcinoma cervix is $2.4 \%$ in India. Approximately 1,00,000 new cases of advanced stages (Stage III and IV) occur per year, which account for nearly (75.7\%) of all new cases detected. Whereas in developed countries, $90 \%$ of cases are diagnosed in early stages (Stage I and II) and only $10 \%$ cases in stage III and IV. This discrepancy is due to lack of mass and regular screening by available methods in our country, which in turn reflects the poor prognosis.

Financial or Other, Competing Interest: None.

Submission 31-07-2016, Peer Review 27-08-2016,

Acceptance 02-09-2016, Published 12-09-2016.

Corresponding Author:

Dr. Kuljit Kaur

W/o. Dr. Harpreet Singh,

Room No. 49, PG-Hostel,

Bharati Vidyapeeth Medical College and Hospital,

Sangli.

E-mail: dr.kuljitkaur@yahoo.com

DOI: $10.14260 /$ jemds $/ 2016 / 1224$

(c) $($ ) $(?$
Prompted by the need for optimal strategies for cervical cancer screening in low resource settings, the role of visual inspection with acetic acid (VIA) and visual inspection with Lugol's iodine (VILI) has been widely studied in several recent studies, which suggest that VIA and VILI closely match the Pap smear in its performance in detecting cervical cancer precursor. ${ }^{1}$ Cancer cervix has been considered preventable because it has a long pre-invasive state. Cancer cervix has been considered preventable, because it has a long pre-invasive state. Invasive carcinoma develops from precancerous lesions; i.e.

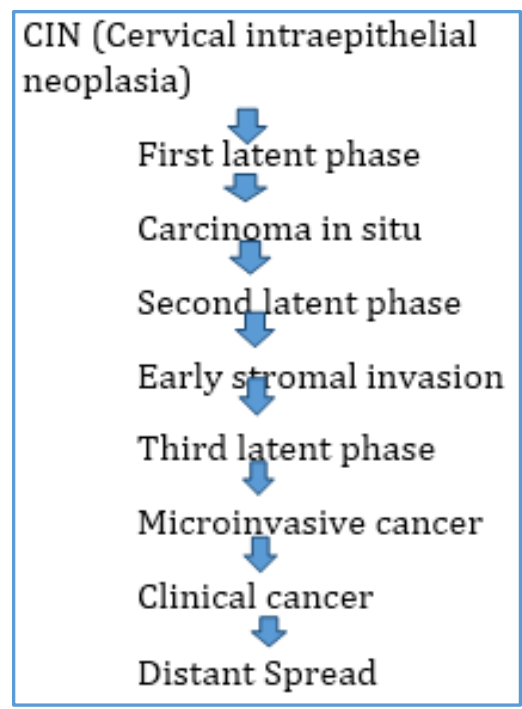


It is observed that mild dysplasia takes 5 years to change to CIS, moderate dysplasia takes 3 years to change to CIS and severe dysplasia takes 1 year to change to CIS. Then there is a latent period of almost 10 years or more for carcinoma in situ to become invasive cervical cancer. Hence, this period can be made useful for early detection.

The most effective method of screening employed in the developed world has been cytology based using Pap smears which has contributed considerably to reducing incidence of and mortality from cervical cancer.

However, this method of screening requires excessive resources in terms of laboratories, equipment, trained personnel and transport of specimens. ${ }^{2}$ This has led to a search for alternative screening methods that can be more costeffective for application in low-resources settings. Visual inspection-based screening tests, such as naked eye visual inspection or 'down staging,' visual inspection with 3-5\% acetic acid (VIA), VIA with magnification (VIAM) and Visual inspection post application of Lugol's iodine (VILI) are a set of alternative screening mechanisms, which have been studied for their effectiveness in low and middle income countries including India. ${ }^{3}$

\section{AIMS AND OBJECTIVES}

To evaluate the sensitivity, specificity, positive predictive value and accuracy of Visual Inspection with Acetic Acid and Lugol's iodine as a screening method for pre-malignant and malignant lesions of cervix.

\section{METHODS AND MATERIALS}

The present study was done on Gynaecological patients attending outpatient Department of Obstetrics and Gynaecology in Bharati Vidyapeeth Medical College and Hospital, Sangli. After taking a detailed history and consent for the screening, the data was collected. Total 131 patients were included in the study and were screened with Cervical cytology, VIA and VILI as screening methods for pre-cancerous and cancerous lesions of cervix. Patients positive for cervical cytology or VIA or VILI were subjected to colposcopy and colpo-guided biopsy if colpo positive.

\section{Inclusion Criteria}

Women of the age of 35 to 65 yrs. with gynaecological complaints.

\section{Exclusion Criteria}

1. Females with active bleeding per vaginum; 2 . Patients with frank growth on cervix; 3. Post hysterectomy patients; 4 . Females who have never been sexually active.

\section{RESULTS}

We screened 131 patients with gynaecological complaints and the data was analysed. Out of 131 patients, maximum patients i.e. 74 patients $(56.4 \%)$ were in age group $35-44$ years. So women in reproductive age group should be offered screening for carcinoma of cervix; 60 patients $(45.8 \%)$ were second paras followed by multiparous patients. The most common complaint is $\mathrm{p} / \mathrm{v}$ discharge, i.e. 113 (58\%) patients. Almost equal number of patients, i.e. 37 (28.5\%) and $36(28.2 \%)$ had normal looking cervix and Erosions on cervix respectively. On Pap smear examination of 131 patients, 78 patients (59.6\%) were normal and $39(29.8 \%)$ had inflammatory smear. VIA was done for 131 patients; 34 patients (25.9\%) were positive for VIA; 2 patients $(1.6 \%)$ were positive for carcinoma. VILI was done in all 131 patients. Only mustard yellow/canary yellow areas were considered positive and area of partial uptake were considered negative; 37 patients $(28.2 \%)$ positive for VILI, 2 patients $(1.6 \%)$ were positive for carcinoma. Colposcopy was done for 56 patients and 24 patients (42.9) were diagnosed with chronic cervicitis followed by 16 patients $(28.6 \%)$ who had LSIL. Biopsy of only 8 patients was taken and out of which 2 patients $(25 \%)$ were positive for adenocarcinoma and a similar number were positive for invasive carcinoma and 3 (37.5\%) showed CIN1. Good Sensitivity and Specificity of VIA, i.e. $76.9 \%$ and $77.9 \%$ and VILI i.e. $76.9 \%$ and $75.4 \%$ make them better methods to detect precancerous and cancerous lesions of cervix.

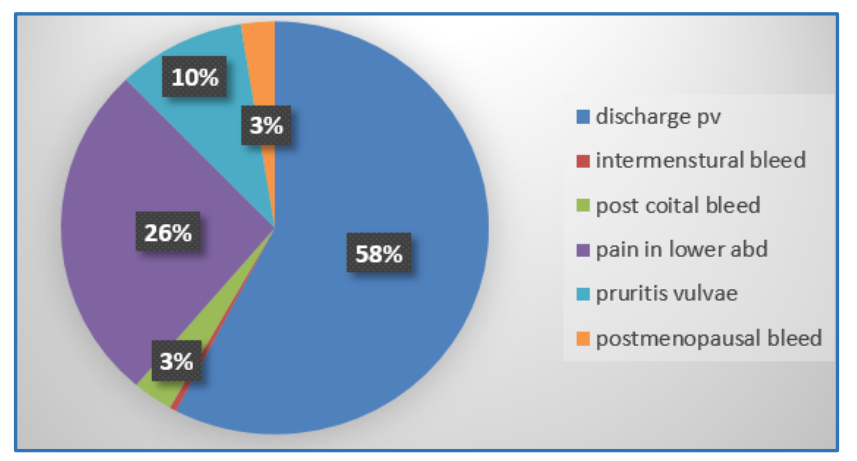

Fig. 1: Distribution of Patients According to Presenting Complaints

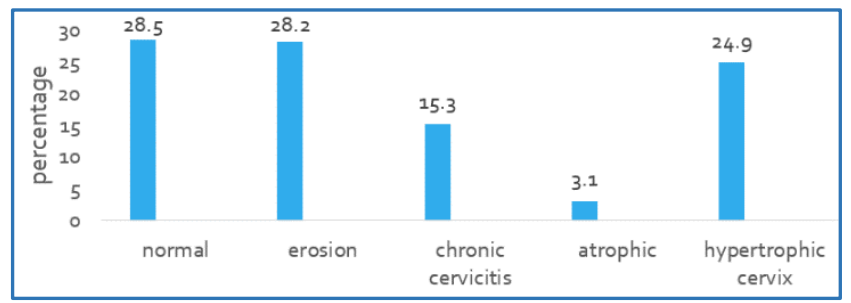

Fig. 2: Distribution of Patients According to Clinical Impression of Cervix on Per Speculum

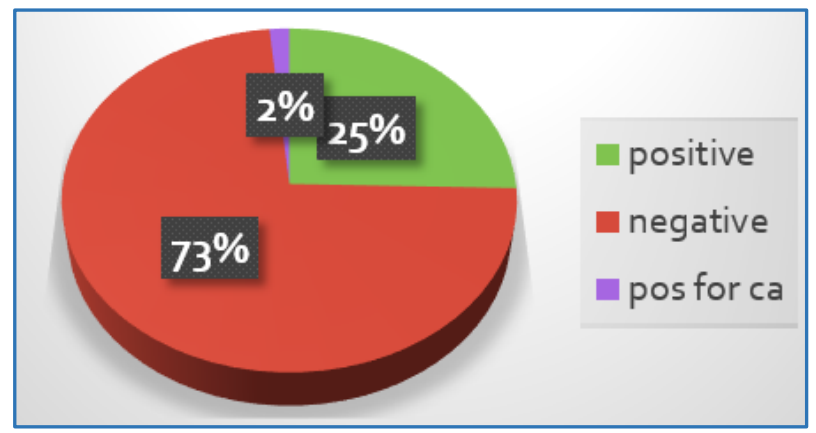

Fig. 3: Distribution of Patients According to Inference on VIA

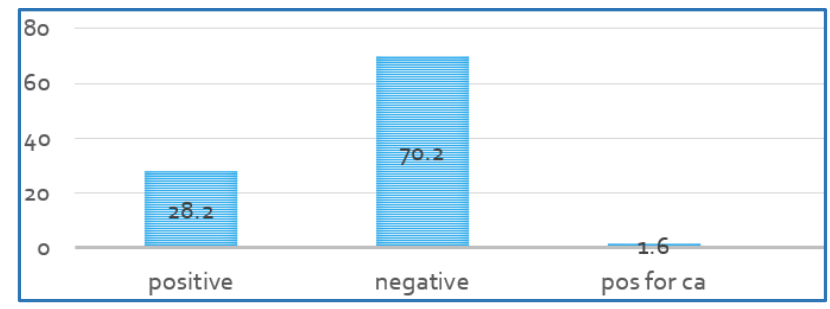

Fig. 4: Distribution of Patients According to VILI 


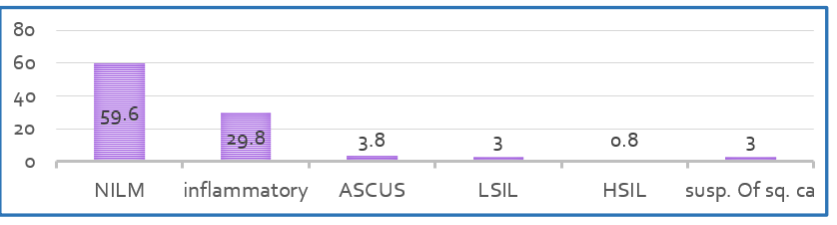

Fig. 5: Distribution of Patients According to Type of STear (PAP) - BETHESDA METHOD

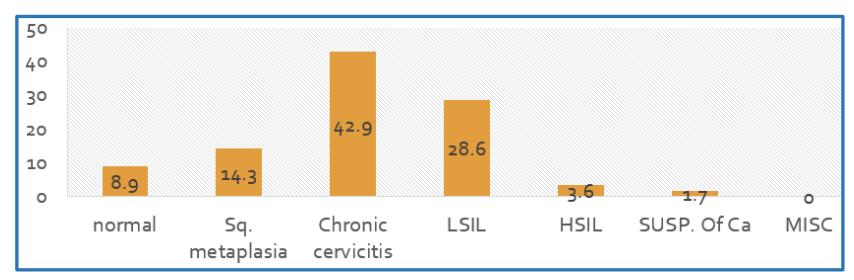

Fig. 6: Distribution According to Colposcopy

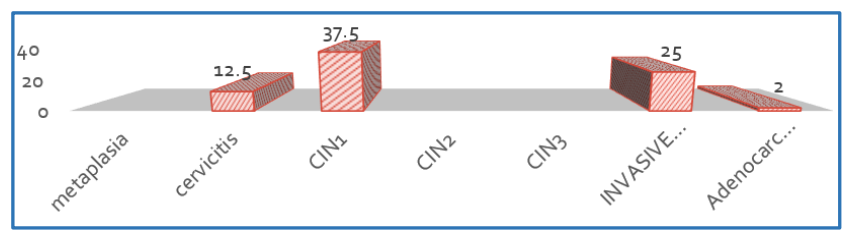

Fig. 7: Distribution of Patients According to Biopsy Findings

Relation between Age and VIA and VILI

\begin{tabular}{|c|c|c|}
\hline $\begin{array}{c}\text { Age } \\
\text { Group }\end{array}$ & $\begin{array}{c}\text { VIA Positive } \\
(\mathbf{n = 3 6 )}\end{array}$ & $\begin{array}{c}\text { VILI Positive } \\
(\mathbf{n = 3 9 )}\end{array}$ \\
\hline $35-44$ & $28(78 \%)$ & $26(67 \%)$ \\
\hline $45-54$ & $6(16.6 \%)$ & $12(30.5 \%)$ \\
\hline $55-64$ & $2(5.4 \%)$ & $1(2.5 \%)$ \\
\hline Total & $\mathbf{3 6}$ & $\mathbf{3 9}$ \\
\hline
\end{tabular}

Patients in the age group of 35 to 44 years of age group were maximum VIA positive, that is $28(78 \%)$ and VILI positive i.e. $26(67 \%)$.
Relation between Parity and VIA and VILI

\begin{tabular}{|c|c|c|}
\hline Parity & $\begin{array}{c}\text { VIA Positive } \\
(\mathbf{n = 3 6 )}\end{array}$ & $\begin{array}{c}\text { VILI Positive } \\
(\mathbf{n = 3 9 )}\end{array}$ \\
\hline Primipara & $6(16.6 \%)$ & $9(23.0 \%)$ \\
\hline Second para & $12(33.4 \%)$ & $15(38.5 \%)$ \\
\hline Multipara & $18(50 \%)$ & $15(38.5 \%)$ \\
\hline Total & $\mathbf{3 6}$ & $\mathbf{3 9}$ \\
\hline
\end{tabular}

Maximum patients who were VIA and VILI positive were para two or more.

Relation between Presenting Complains with VIA and VILI

\begin{tabular}{|c|c|c|}
\hline $\begin{array}{c}\text { Presenting } \\
\text { Complaints }\end{array}$ & $\begin{array}{c}\text { VIA Positive } \\
(\mathbf{n = 3 6 )}\end{array}$ & $\begin{array}{c}\text { VILI Positive } \\
(\mathbf{n = 3 9 )}\end{array}$ \\
\hline No complains & $3(8.3 \%)$ & $2(5.1 \%)$ \\
\hline Discharge per vaginum & $14(39 \%)$ & $16(41 \%)$ \\
\hline Intermenstural bleeding & $1(2.7 \%)$ & $2(5.1 \%)$ \\
\hline Postcoital bleed & $1(2.7 \%)$ & $0(0 \%)$ \\
\hline Pain in lower abdomen & $10(28 \%)$ & $9(23 \%)$ \\
\hline Pruritus Vulvae & $6(16.6 \%)$ & $8(20.7 \%)$ \\
\hline Postmenopausal Bleed & $1(2.7 \%)$ & $2(5.1 \%)$ \\
\hline Total & $\mathbf{3 6 ( 1 0 0 \% )}$ & $\mathbf{3 9 ( 1 0 0 \% )}$ \\
\hline
\end{tabular}

The most common complaint in VIA and VILI positive cases was discharge per vaginum i.e. 14 (39\%) and 16 (41\%) respectively followed by pain in abdomen i.e. 10 (28\%) and 9 (23\%) for VIA and VILI positive.

Relation between Clinical Findings and Visual Screening Methods

\begin{tabular}{|c|c|c|}
\hline Clinical Findings & VIA (n=36) & VILI (n=39) \\
\hline Normal & $15(41.7 \%)$ & $19(48.7 \%)$ \\
\hline Erosion & $6(16.7 \%)$ & $13(33.4 \%)$ \\
\hline Chronic cervicitis & $13(36.2 \%)$ & $5(12.9 \%)$ \\
\hline Atrophic & $1(2.7 \%)$ & $0(0 \%)$ \\
\hline Hypertrophic & $1(2.7 \%)$ & $2(5.0 \%)$ \\
\hline Total & $\mathbf{3 6}(\mathbf{1 0 0} \%)$ & $\mathbf{3 9}(\mathbf{1 0 0} \%)$ \\
\hline
\end{tabular}

Maximum patients who were VIA positive i.e. 15 (41.7\%) and VILI positive i.e. 19 (48.7\%) had clinically normal cervix

\section{Comparison of VIA and VILI}

\begin{tabular}{|c|c|c|c|c|c|}
\hline \multirow{2}{*}{ VIA } & \multicolumn{2}{|c|}{ VILI } & \multirow{2}{*}{ Total } & & \\
\hline & Diseased & Non Diseased & & Sensitivity $=$ (true positive $)=$ & $76.92 \%$ \\
\hline \multirow{2}{*}{ Positive } & 30 & 6 & 36 & Specificity $=($ true negative $)=$ & $93.48 \%$ \\
\hline & $83.30 \%$ & $16.70 \%$ & $100.00 \%$ & Predictive value of a positive test $=$ & $83.33 \%$ \\
\hline \multirow{2}{*}{ Negative } & 9 & 86 & 95 & Predictive value of a negative test $=$ & $90.53 \%$ \\
\hline & $9.50 \%$ & $90.50 \%$ & $100.00 \%$ & Percentage of false negative $=$ & $23.08 \%$ \\
\hline \multirow{2}{*}{ Total } & 39 & 92 & 131 & Percentage of false positives $=$ & $6.52 \%$ \\
\hline & $29.80 \%$ & $70.20 \%$ & $100.00 \%$ & & \\
\hline
\end{tabular}

Chi square $=68.118, \mathrm{p}<0.001$. This is highly Significant.

\section{Comparison of PAP with VIA}

\begin{tabular}{|c|c|c|c|c|c|}
\hline & Clinical Cytology & & & & \\
\hline VIA & Positive & Negative & Total & Sensitivity = (true positive) $=$ & $76.92 \%$ \\
\hline Positive & 10 & 26 & 36 & & \\
\hline & $27.80 \%$ & $72.20 \%$ & $100.00 \%$ & Specificity= (true negative) $=$ & $77.97 \%$ \\
\hline Negative & 3 & 92 & 95 & & \\
\hline & $3.20 \%$ & $96.80 \%$ & $100.00 \%$ & & \\
\hline Total & $\mathbf{1 3}$ & $\mathbf{1 1 8}$ & $\mathbf{1 3 1}$ & & \\
\hline & $\mathbf{9 . 9 0 \%}$ & $\mathbf{9 0 . 1 0} \%$ & $\mathbf{1 0 0 . 0 0} \%$ & & \\
\hline
\end{tabular}

Chi square $=17.703, p=0.00$. Highly significant. 
Comparison of VILI and Cervical Cytology

\begin{tabular}{|c|c|c|c|c|c|}
\hline & Clinical Cytology & & & & \\
\hline VILI & Positive & Negative & Total & Sensitivity = (true positive) $=$ & $76.92 \%$ \\
\hline Positive & 10 & 29 & 39 & & \\
\hline & $25.60 \%$ & $74.40 \%$ & $100.00 \%$ & Specificity = (true negative) $=$ & $75.42 \%$ \\
\hline Negative & 3 & 89 & 92 & & \\
\hline & $3.30 \%$ & $96.70 \%$ & $100.00 \%$ & & \\
\hline
\end{tabular}

Comparison Between VIA and Biopsy

\begin{tabular}{|c|c|c|c|c|c|}
\hline \multirow{2}{*}{ VIA } & \multicolumn{2}{|c|}{ Cervical Biopsy } & \multirow{2}{*}{ Total } & & \\
\cline { 2 - 3 } \cline { 5 - 6 } & Diseased & Non Diseased & & Sensitivity = (true positive) $=$ & $76.92 \%$ \\
\hline \multirow{2}{*}{ Positive } & 10 & 26 & 36 & Specificity= (true negative) $=$ & $77.97 \%$ \\
\cline { 2 - 6 } & $27.80 \%$ & $72.20 \%$ & $100.00 \%$ & Predictive value of a positive test $=$ & $27.78 \%$ \\
\hline \multirow{2}{*}{ Negative } & 3 & 92 & 95 & Predictive value of a negative test $=$ & $96.84 \%$ \\
\cline { 2 - 6 } & $3.20 \%$ & $96.80 \%$ & $100.00 \%$ & Percentage of false negative $=$ & $23.08 \%$ \\
\hline \multirow{2}{*}{ Total } & 13 & 118 & 131 & Percentage of false positives $=$ & $2.03 \%$ \\
\cline { 2 - 6 } & $9.90 \%$ & $90.10 \%$ & $100.00 \%$ & & \\
\hline
\end{tabular}

Chi square is $17.703 ; p=0.000$. Highly significant.

\section{Comparison of VILI and Biopsy}

\begin{tabular}{|c|c|c|c|c|c|}
\hline \multirow{2}{*}{ VILI } & \multicolumn{2}{|c|}{ Cervical Biopsy } & \multirow{2}{*}{ Total } & & \\
\hline & Diseased & Non Diseased & & Sensitivity $=($ true positive $)=$ & $76.92 \%$ \\
\hline \multirow{2}{*}{ Positive } & 10 & 29 & 39 & Specificity $=$ (true negative) $=$ & $75.42 \%$ \\
\hline & $25.60 \%$ & $74.40 \%$ & $100.00 \%$ & Predictive value of a positive test $=$ & $25.64 \%$ \\
\hline \multirow{2}{*}{ Negative } & 3 & 89 & 92 & Predictive value of a negative test $=$ & $96.74 \%$ \\
\hline & $3.30 \%$ & $96.70 \%$ & $100.00 \%$ & Percentage of false negative $=$ & $23.08 \%$ \\
\hline \multirow{2}{*}{ Total } & 13 & 118 & 131 & Percentage of false positives $=$ & $24.58 \%$ \\
\hline & $9.90 \%$ & $90.10 \%$ & $100.00 \%$ & & \\
\hline
\end{tabular}

Chi square $=15.347 ; \mathrm{P}=0.00$. Highly significant.

\section{DISCUSSION}

Cervical cancer is one of the leading causes of cancer deaths in women worldwide with an estimated 4,70,600 new cases and $2,33,400$ deaths per year. ${ }^{4} \mathrm{~A}$ quarter of burden is experienced in India, where 1,26,000 new cases and 71,000 deaths attributable to cervical cancer annually. Cervical cancer is a potentially preventable cancer. It is preceded by premalignant lesions, which take as many as 5-15 years to progress to invasive cancer. The main screening method has been Pap smear, which is available to a small percentage of population. Cytology based screening programs are difficult to organise in India owing to limited infrastructure, trained personnel and funds. ${ }^{5}$ Thus in developing countries like ours, there is need for alternative screening strategies which are available on large scale, cost-effective, easy and can be done by a paramedical worker.

Visual screening tests are inherently subjective and provider dependent. This leads to high false positive and low specificity. At best they have moderate sensitivity, but one which is higher than cytology in many low resource settings.

The subjective nature of visual testing is much reflected by wide range in test performance characteristics in various settings and limited reproducibility. 6

Visual methods of screening are being investigated in few years as screening methods for detection of carcinoma cervix. Some workers attempted to do Unaided Visual Inspection of Cervix to identify cases suspicious for Precancer and Cancer. This method was to have low positive predictive value ranging from $2-6 \% .^{7}$ Then attempts made to visualise cervix for precancerous lesion after application of 3-5\% acetic acid and Lugol's iodine. VIA is more sensitive than conventional Cytology in detecting intraepithelial lesions. ${ }^{8}$ And the colour changes with VILI are easier to appreciate. ${ }^{9,10,11}$ The advantage of these methods is that the results are immediately available and one can apply "See and Treat" policy in suitable cases.

\section{CONCLUSION}

1. On comparing VIA and VILI and Pap smear, a significant correlation was found amongst them.

2. In low resource settings, screening by Pap smear has not been successful in reducing incidence of cervical cancer. The disadvantage are that it is not feasible on large scale basis.

3. VIA and VILI are cheaper and easily available and can be used by medical and paramedical personnel on a large scale basis.

4. Biopsy can be taken from VIA and VILI positive areas in the field, even in situations when a colposcope is not available.

5. Aim at reducing the incidence of cervical cancer by identifying the causes and risk factors is indeed an uphill task. Cancer screening is the main weapon for early detection of cervical cancer at a premalignant stage.

6. Screening by Pap smear is not feasible due to several limitations like inadequate coverage of large population, lack of infrastructure and resource required for cytological screening.

7. By VIA and VILI, mass screening can be done at a very low, affordable price even at a low resource setting by trained medical and paramedical staff and treatment modalities can be offered. Hence, by these screening tools a large number of population that go undetected can be screened and treated.

8. Still larger studies are required to apply it universally. 


\section{REFERENCES}

1. Sankaranarayanan $\mathrm{R}$, wesley $\mathrm{R}$, Thara $\mathrm{S}$, et al. Test characteristics of visual inspection with $4 \%$ acetic acid (VIA) and lugol's iodine (VILI) in cervical cancer screening in Kerala, India. Int J Cancer 2003;106(3):404-8.

2. Baliga BS. Principles and practice of colposcopy. $1^{\text {st }}$ edn. Jaypee Brother 2004.

3. Sankaranarayanan R, Basu P, Wesley RS, et al. Accuracy of visual screening for cervical cancer neoplasia: results from an IARC multicentre study in India and Africa. International Journal of Cancer 2004;110(6):907-13.

4. Basu P, Sankaranarayanan R, Mandal R, et al. Evaluation of downstaging in detection of cervical neoplasia in Kolkata, India. Int J Cancer 2002;100(1):92-6.

5. Shastri SS, Dinshaw K, Amin G, et al. Concurrent evaluation of visual, cytological and HPV testing as screening methods for early detection of cervical neoplasia in Mumbai, India. Bull World Organ 2005;83(3):186-94.

6. Sankaranarayanan R, Chatterji R, Shastri SS, et al. Accuracy of human papillomavirus testing in primary screening of cervical neoplasia: results from a multicenter study in India. Int J Cancer 2004;112(2):341-7.
7. IARC Handbooks of Cancer Prevention: cervix cancer screening. Vol.10. Lyon: IARC Press 2005.

8. Blumenthal PD, Gaffkin L, Chirenje ZM, et al. Adjuvant testing for cervical cancer in low resource setting with visual inspection, HPV and the pap smear. Int J Gynecol Obstet 2001;72(1):47-53.

9. Bhatla N, Mukhopadhyay A, Joshi S, et al. Visual inspection for cervical cancer screening: evaluation by doctor versus paramedical worker. Ind J Cancer 2004;41(1):32-6.

10. Denny L, Sankaranarayanan R. Secondary prevention of cancer. Int J Gynecol Obstet 2006; 94(Suppl 1):S65-S70.

11. Sarian LO, Derchain SF, Naud P, et al. Evaluation of visual inspection with acetic acid, lugol's iodine, cervical cytology and HPV testing as cervical cancer screening tools in Latin America. This report refers to partial results from the LAMS (Latin AMerican Screening) study. J Med Screen 2005;12(3):142-149. 